\title{
Socio-economic and rural-urban differences in healthcare and catastrophic health expenditures among cancer patients in China: analysis of the China Health and Retirement Longitudinal Study
}

\author{
Yang Zhao ( $\square$ Wzhao@georgeinstitute.org.cn ) \\ The George Institute for Global Health \\ Shenglan Tang \\ Duke University \\ Wenhui Mao \\ Duke University \\ Tomi F Akinyemiju \\ Duke University
}

\section{Research}

Keywords: Cancer study, healthcare, health expenditure, rural-urban difference, China

Posted Date: September 13th, 2021

DOl: https://doi.org/10.21203/rs.3.rs-889381/v1

License: (c) (i) This work is licensed under a Creative Commons Attribution 4.0 International License.

Read Full License

Version of Record: A version of this preprint was published at Frontiers in Public Health on January 11th, 2022. See the published version at https://doi.org/10.3389/fpubh.2021.779285. 


\section{Abstract \\ Background}

In China, cancer deaths account for one-fifth of all deaths and exert a heavy toll on patients, families, healthcare systems, and society as a whole. This study aims to examine socio-economic and rural-urban differences in treatment, healthcare service utilization and catastrophic health expenditure (CHE) among Chinese cancer patients, and to investigate the relationship between different treatment types and healthcare service use as well as incidence of $\mathrm{CHE}$.

\section{Methods}

We analyzed a nationally representative sample from the China Health and Retirement Longitudinal Study including 17,224 participants in 2011 and 19,569 participants in 2015. Multivariable regression models were performed to investigate the association of cancer treatments with healthcare service utilization and CHE.

\section{Results}

The age-adjusted prevalence of cancer is $1.37 \%$ for 2011 and $1.84 \%$ for 2015 . Approximately half of the cancer patients utilized treatment for their disease, with a higher proportion of urban residents $(54 \%)$ than rural residents (46\%) receiving cancer treatment in 2015 . CHE declined by $22 \%$ in urban areas $(25 \%$ in 2011 and $19 \%$ in 2015) but increased by $31 \%$ in rural areas (25\% in 2011 to $33 \%$ in 2015). There was a positive relationship between cancer treatment and outpatient visit $(\mathrm{OR}=2.098,95 \% \mathrm{Cl}=1.453,3.029)$, admission to hospital $(\mathrm{OR}=1.961,95 \% \mathrm{Cl}=1.346,2.857)$ and $\mathrm{CHE}(\mathrm{OR}=1.796,95 \% \mathrm{Cl}=1.231,2.620)$. Chemotherapy and surgery were each associated with a 2-fold increased risk of CHE.

\section{Conclusions}

Meaningful changes to improve health insurance benefit packages are needed to ensure universal, affordable and patient-centered health coverage for the Chinese cancer patients.

\section{Background}

Chronic non-communicable diseases (NCDs) has become the leading cause of global disease burden. Cancers rank as a major contributor to a burden on the healthcare systems in several countries. In China, evidence suggested that there were over 4 million new cancer cases diagnosed, and almost 3 million cancer deaths occurred in 2018, which accounted for a high percentage of total cancer cases (about $23 \%$ ) and deaths (30\%) worldwide [1]. In China, cancer deaths account for one-fifth of all deaths, and exerts a heavy toll on patients, families and the whole health systems. 
To mitigate the healthcare and financial burden of NCDs including cancers, the central government of China has launched a new round of comprehensive healthcare system reforms since 2009, focusing on healthcare delivery, basic public health service, medical insurance, essential medicine system and public hospital reform. Most of these measures were designed to improve the access to quality and affordable care for patients with NCDs and health outcomes [2, 3]. In 2015, URBMI (Urban Residents Basic Medical Insurance) and NCMS (New Rural Cooperative Medical System) were integrated into one urban-rural resident health insurance scheme, which enhance the financial risk protection for patients with cancers [4, 5]. In addition, the Critical IIIness Health Insurance and supplementary medical insurance programs were developed to offer extra benefits packages to citizens with severe chronic diseases. The reform and consolidation of three-level medical institutions (including primary healthcare centers, secondary hospitals and tertiary hospitals) aimed at providing coordinated diagnoses, treatment, and follow-up care to Chinese cancer patients [6]. Despite the launch of China healthcare system reform in 2009, few empirical data have evaluated the impact of the comprehensive health reforms on cancer health expenditure.

We hypothesize that reformed medical insurances and healthcare delivery systems could further reduce catastrophic health expenditures (CHE) among patients with cancer in both rural and urban regions of China. The CHE in this study is defined as the point at which annual household healthcare expenses exceeded $40 \%$ of non-food household expenditures, a measure of degree of financial risk to patients with cancer. Although the new round of health reforms have been implemented at the national level, it may take time to translate the investments into equitable health service use among people with different socio-economic status (SES) [7].

Previous research had reported the relationship between cancers and socio-economic characteristics, including China, showing that higher socio-economic status is associated with greater likelihood of routine screening, incidence of cancer, cancer treatment utilization and better survival. [8-12]. Other studies in China have examined socio-economic and gender inequalities in the incidence of cancer as well as mortality [17, 18], and differences in treatment utilization [19]. Researchers also investigated socio-economic differences among patients with NCDs, such as hypertension, diabetes, stroke, chronic obstructive pulmonary disease as well as multiple chronic diseases [20-25]. However, there is limited evidence of the financial burden of cancer care in China across socio-economic groups. [26] In addition, few studies have evaluated whether CHE varies by treatment types (eg. Chinese traditional or western medicine), or estimated the impact of the 2009 health reforms on health service utilization among cancer patients [13-16].

Our research is with the aim of: (1) investigating changes of the burden and socio-economic differences in CHE among Chinese adults with cancers; (2) assessing whether CHE varies by treatment type, and (3) examining relationships between different types of cancer therapy and healthcare service use as well as the incidence of $\mathrm{CHE}$.

\section{Methods}




\section{Data Source}

In this study, data was obtained from the China Health and Retirement Longitudinal Study (CHARLS) in 2011 and 2015, and details of the study methodology have been published elsewhere [27]. The CHARLS is a biennial survey, which aimed to be representative of Chinese adults aged 45 years and above. CHARLS study design is similar to the Health and Retirement Study (HRS) and other established related ageing surveys [27]. Study questionnaires covered the domains of demographics, health status and functioning, healthcare and insurance, household income and consumption as well as clinical risk factors (blood pressures) [27].

To ensure ample representativeness at the national level, CHARLS sampled 150 counties and 450 villages/urban communities across 28 provinces, using multi-stage stratified probability-proportionate-tosize (PPS) sampling. A total of 17,708 and 21,097 individuals were interviewed in 2011 (baseline) and 2015 (3rd wave). Final data were available for 17,224 participants in 2011 and 19,569 participants in 2015 , after excluding participants with missing values of socio-demographic and/or cancer treatment information. A total of 234 individuals (in 2011) and 368 participants (in 2015) self-reported clinicallydiagnosed cancers.

\section{Cancer Care Indicators}

We identified six types of cancer treatments/therapies: Chinese traditional medication (TCM) only, western modern medication only (refers to taking western medication excluding TCM and chemotherapy medications for cancer treatment), TCM \& western medication, surgery, chemotherapy and radiation therapy. The overall treatment was defined as receipt of any TCM or Western medicine treatment (having one or more types of the five therapies). In terms of health services utilization, this study included 1) outpatient care (participants were asked whether they had any outpatient visit during last month); 2) inpatient care (participants were asked whether they had any hospitalization and how many nights of hospital stay during last year). Medical expenditures were also collected in CHARLS, which included total health expenditure, reimbursed part of expenditure, and out-of-pocket spending for outpatient services in the past month and the inpatient care in the past year.

We apply the indicator of CHE to measure the financial risk or economic burden for the household with family member suffering cancers. There were two common criteria of CHE definition: 1) out-of-pocket payments (OOP) over $40 \%$ of the household's capacity to pay (using household's expenditure on non-food consumption as proxy), and 2) over $10 \%$ of total household income/expenditure [28-30]. Following previous studies, we defined CHE as OOP for healthcare equaling or exceeding $40 \%$ of the household's capacity to pay [29]. The OOP health expenditure (household's capacity to pay) was considered as the numerator (denominator). CHE was coded as "yes" if the proportion over $40 \%$ and "no" if not.

The SES was assessed using the Socio-economic Index score, and calculated based on educational attainment, occupation and household consumption expenditure. This research used Li's scale for Chinese residents (version 2010) [31] as a standard scale. This scale, commonly used in social science 
research in China [32-35], was modified based on the scale first proposed by Duncan [36]. Educational level, occupation and household consumption expenditure were classified to assign scores and summarized as a comprehensive Socio-economic Index score. Based on the Socio-economic Index scores, all subjects were classified as low ( $<10$ scores) and high SES class ( $\geq 10$ scores).

\section{Statistical Analysis}

This study applied Chi-square tests to examine the SES differences in types of cancer treatment, outpatient and inpatient service use as well as incidence of catastrophic medical expenditure. For continuous variables including nights of hospitalization and OOPE of health care, we used t-tests to analyze SES group differences. Based on the pooled two-wave data of cancer patients, we performed multivariable logistic regressions to investigate the association of cancer treatment with outpatient visit, hospitalization as well as incidence of $\mathrm{CHE}$, adjusting for socio-demographic factors Covariates in the regression analyses included gender, age, marital condition, education status, location residence, region in China and social health insurance enrolled.

To explore differential relationships across the wealth groups, we also conducted subgroup analyses with logistic regression models stratified by the SES Index. The adjusted odds ratio (OR) and $95 \%$ confidence intervals $(\mathrm{Cl})$ were reported for logistic regression analyses in this study. The weighted prevalence of cancers were also reported considering nonresponse data and the complex, multistage design of CHARLS study. $P$ values less than 0.05 were considered as statistically significant. Statistical analyses were conducted using STATA software (version 15.0; StataCorp LLC College Station, Texas, United States).

\section{Results}

Table 1 presents the socio-demographic characteristics of participants and cancer patients among Chinese people aged 45 years and above in 2011 and 2015. The prevalence of cancer increased from $1.36 \%(234$ of 17,224$)$ in 2011 to $1.88 \%$ (368 of 19,569) in 2015 . The age-adjusted prevalence of cancer is $1.37 \%$ for 2011 and $1.84 \%$ for 2015 . The prevalence of cancer was higher in people who: were female; had social health insurance; were located in the eastern region and unemployed individuals than those who: were male; without health insurance, lived in the western region and being employed 
Table 1

The prevalence of cancer among Chinese adults in 2011 and 2015

\begin{tabular}{|c|c|c|c|c|c|c|c|c|}
\hline & 2011 & & & & 2015 & & & \\
\hline & $\mathrm{N}$ & $\mathrm{n}$ & $\%(1)$ & $\%(2)$ & $\mathrm{N}$ & $\mathrm{n}$ & $\%(1)$ & $\%(2)$ \\
\hline Total & 17,224 & 234 & 1.36 & 1.25 & 19,569 & 368 & 1.88 & 2.05 \\
\hline \multicolumn{9}{|l|}{ Gender } \\
\hline Male & 8,397 & 86 & 1.02 & 0.90 & 9,526 & 116 & 1.22 & 1.56 \\
\hline Female & 8,827 & 148 & 1.68 & 1.58 & 10,043 & 252 & 2.51 & 2.51 \\
\hline \multicolumn{9}{|l|}{ Age (years) } \\
\hline $45-55$ & 6,255 & 89 & 1.42 & 1.23 & 6,699 & 116 & 1.73 & 2.14 \\
\hline $55-65$ & 6,355 & 76 & 1.20 & 1.16 & 6,611 & 134 & 2.03 & 2.09 \\
\hline$\geq 65$ & 4,614 & 69 & 1.50 & 1.38 & 6,259 & 118 & 1.89 & 1.90 \\
\hline \multicolumn{9}{|l|}{ Marital status } \\
\hline Married/partnered & 14,970 & 214 & 1.43 & 1.32 & 16,891 & 324 & 1.92 & 2.07 \\
\hline Never married/divorced & 2,254 & 20 & 0.89 & 0.88 & 2,678 & 44 & 1.64 & 1.91 \\
\hline \multicolumn{9}{|l|}{ Residence location } \\
\hline Urban area & 6,967 & 103 & 1.48 & 1.18 & 7,908 & 164 & 2.07 & 2.30 \\
\hline Rural area & 10,257 & 131 & 1.28 & 1.32 & 11,661 & 204 & 1.75 & 1.79 \\
\hline \multicolumn{9}{|l|}{ Region } \\
\hline East & 6,572 & 112 & 1.70 & 1.47 & 7,477 & 156 & 2.09 & 2.50 \\
\hline Central & 6,489 & 78 & 1.20 & 1.17 & 7,236 & 137 & 1.89 & 1.84 \\
\hline West & 4,163 & 44 & 1.06 & 0.96 & 4,856 & 75 & 1.54 & 1.50 \\
\hline \multicolumn{9}{|l|}{ Health insurance } \\
\hline No & 1,352 & 13 & 0.96 & 0.70 & 3,109 & 42 & 1.35 & 1.23 \\
\hline Yes & 15,872 & 221 & 1.39 & 1.30 & 16,460 & 326 & 1.98 & 2.23 \\
\hline \multicolumn{9}{|l|}{ Education level } \\
\hline Primary school/below & 11,476 & 156 & 1.36 & 1.25 & 13,517 & 258 & 1.91 & 2.16 \\
\hline Middle school/above & 5,748 & 78 & 1.36 & 1.26 & 6,052 & 110 & 1.82 & 1.84 \\
\hline
\end{tabular}




\section{Employment status}

$\begin{array}{lllllllll}\text { No } & 5,817 & 113 & 1.94 & 1.73 & 6,791 & 193 & 2.84 & 2.70 \\ \text { Yes } & 11,407 & 121 & 1.06 & 0.95 & 12,778 & 175 & 1.37 & 1.63\end{array}$

Note: \% (1), the unweighted prevalence of cancers; \% (2), the weighted prevalence of cancers. The age-adjusted prevalence of cancer is $1.37 \%$ for 2011 and $1.84 \%$ for 2015.

Table 2 shows the treatment \therapy condition among Chinese adults with cancers. Overall, approximately half of the cancer patients utilized treatment for their disease, with a higher proportion of urban residents (54\%) than rural residents (46\%) receiving cancer treatment in 2015. In addition, a higher proportion of high versus low SES patients utilized cancer treatment. Taking western medication and surgery were the two main type of treatment for cancers. People with a high SES level received more medication treatment, surgery and chemotherapy than low SES patients in China. 
Table 2

The proportion of cancer treatment in China, by the socioeconomic group

\section{Variables}

2011

$\begin{array}{llllllll}\mathrm{N} & \mathrm{n} & \% & \mathrm{P} \text { value } & \mathrm{N} & \mathrm{n} & \% & \text { P value }\end{array}$
2015

\section{Overall treatment}

Urban area

Rural area

SES Index, low level

SES Index, high level

All

TCM only

Urban area

Rural area

SES Index, low level

SES Index, high level

All

Western medication only

Urban area

Rural area

SES Index, low level

SES Index, high level

All

TCM \& Western medication

Urban area

Rural area

SES Index, low level
$103 \quad 54$

$131 \quad 68$

$156 \quad 81$

$78 \quad 41$

$234 \quad 122$
52.43

51.91

$51.92 \quad 0.926$

52.56

52.14 


\begin{tabular}{|c|c|c|c|c|c|c|c|c|}
\hline \multirow{2}{*}{$\begin{array}{l}\text { Variables } \\
\text { SES Index, high level }\end{array}$} & \multicolumn{4}{|c|}{2011} & \multicolumn{4}{|c|}{2015} \\
\hline & 78 & 6 & 7.69 & & 177 & 27 & 15.25 & \\
\hline All & 234 & 24 & 10.26 & & 368 & 49 & 13.32 & \\
\hline \multicolumn{9}{|l|}{ Chemotherapy } \\
\hline Urban area & 103 & 15 & 14.56 & 0.199 & 164 & 25 & 15.24 & 0.907 \\
\hline Rural area & 131 & 12 & 9.16 & & 204 & 32 & 15.69 & \\
\hline SES Index, low level & 156 & 17 & 10.90 & 0.664 & 191 & 28 & 14.66 & 0.648 \\
\hline SES Index, high level & 78 & 10 & 12.82 & & 177 & 29 & 16.38 & \\
\hline All & 234 & 27 & 11.54 & & 368 & 57 & 15.49 & \\
\hline \multicolumn{9}{|l|}{ Surgery } \\
\hline Urban area & 103 & 28 & 27.18 & 0.664 & 164 & 47 & 28.66 & 0.314 \\
\hline Rural area & 131 & 39 & 29.77 & & 204 & 49 & 24.02 & \\
\hline SES Index, low level & 156 & 47 & 30.13 & 0.474 & 191 & 41 & 21.47 & 0.036 \\
\hline SES Index, high level & 78 & 20 & 25.64 & & 177 & 55 & 31.07 & \\
\hline All & 234 & 67 & 28.63 & & 368 & 96 & 26.09 & \\
\hline \multicolumn{9}{|l|}{ Radiation therapy } \\
\hline Urban area & 103 & 7 & 6.80 & 0.463 & 164 & 14 & 8.54 & 0.429 \\
\hline Rural area & 131 & 6 & 4.58 & & 204 & 13 & 6.37 & \\
\hline SES Index, low level & 156 & 9 & 5.77 & 0.840 & 191 & 14 & 7.33 & 0.996 \\
\hline SES Index, high level & 78 & 4 & 5.13 & & 177 & 13 & 7.34 & \\
\hline All & 234 & 13 & 5.56 & & 368 & 27 & 7.34 & \\
\hline \multicolumn{9}{|c|}{ *Overall treatment defined as receipt of any TCM or Western medicine treatment } \\
\hline \multicolumn{9}{|c|}{ **Western modern medication in this study exclude chemotherapy medications } \\
\hline
\end{tabular}

Table 3 describes trends in health service utilization, health spending and $\mathrm{CHE}$ among Chinese cancer patients between 2011 and 2015. There was increasing health service utilisation among cancer patient in China from 2011 to 2015 (Outpatient visit, 26-30\%; Admission rate, 23-30\%; Average hospitalization nights, 3.41 to 3.81). In 2011, residents living in rural areas had a higher proportion of outpatient visits but less OOPE for outpatient care than urban residents. However, by 2015 , this gap had narrowed for 
outpatient visits, OOPE for outpatient care more than tripled in rural areas (mean 517 in 2011 versus 3893 in 2015 and declined significantly (mean 4494 in 2011 and 1564 in 2015) in urban areas. Between 2011 and 2015 , CHE declined by $22 \%$ in urban areas (25\% in 2011 and $19 \%$ in 2015 ) but increased by $31 \%$ in rural areas (25\% in 2011 to $33 \%$ in 2015). In 2011, low SES cancer patients had significantly lower OOPE for inpatient care compared with high SES patients, however by 2015 this gap had narrowed and was no longer significant. In 2015, there was no significant difference in CHE among low versus high SES cancer patients, although the prevalence of CHE was increased slightly in both groups compared with 2011 . 
Table 3

Health service utilisation and health spending among cancer patients in China, by the socioeconomic group

\begin{tabular}{|c|c|c|c|c|}
\hline & \multicolumn{2}{|l|}{2011} & \multicolumn{2}{|l|}{2015} \\
\hline & $\%$ & $P$ value & $\%$ & $P$ value \\
\hline \multicolumn{5}{|c|}{ Outpatient visits, last month (\%) } \\
\hline Urban area & 18.45 & 0.007 & 26.22 & 0.115 \\
\hline Rural area & 34.35 & & 33.82 & \\
\hline SES Index, low level & 23.72 & 0.247 & 29.84 & 0.798 \\
\hline SES Index, high level & 30.77 & & 31.07 & \\
\hline All & 26.07 & & 30.43 & \\
\hline \multicolumn{5}{|c|}{ Admission rate, last year (\%) } \\
\hline Urban area & 25.24 & 0.401 & 32.32 & 0.362 \\
\hline Rural area & 20.61 & & 27.94 & \\
\hline SES Index, low level & 21.15 & 0.439 & 25.65 & 0.065 \\
\hline SES Index, high level & 25.64 & & 34.46 & \\
\hline All & 22.65 & & 29.89 & \\
\hline \multicolumn{5}{|c|}{ Nights in hospital, last year (mean) } \\
\hline Urban area & 4.20 & 0.115 & 4.09 & 0.313 \\
\hline Rural area & 2.79 & & 3.58 & \\
\hline SES Index, low level & 2.96 & 0.136 & 3.46 & 0.246 \\
\hline SES Index, high level & 4.32 & & 4.18 & \\
\hline All & 3.41 & & 3.81 & \\
\hline \multicolumn{5}{|c|}{ OOPE for outpatient care*, CNY (mean) } \\
\hline Urban area & 4494 & 0.008 & 1564 & 0.107 \\
\hline Rural area & 517 & & 3893 & \\
\hline
\end{tabular}

Note: In this study, we defined catastrophic health expenditure as medical OOPE equalling or exceeding $40 \%$ of the household's expenditure on non-food consumption.

* Out-of-pocket expenditure among cancer patients with outpatient visit

** Out-of-pocket expenditure among cancer patients with inpatient care 


\begin{tabular}{|c|c|c|c|c|}
\hline & 2011 & & 2015 & \\
\hline SES Index, low level & 2121 & 0.278 & 2225 & 0.189 \\
\hline SES Index, high level & 1093 & & 3826 & \\
\hline All & 1820 & & 3025 & \\
\hline \multicolumn{5}{|c|}{ OOPE for inpatient care*, CNY (mean) } \\
\hline Urban area & 19612 & 0.175 & 16566 & 0.468 \\
\hline Rural area & 12477 & & 16153 & \\
\hline SES Index, low level & 10372 & 0.028 & 13851 & 0.189 \\
\hline SES Index, high level & 25225 & & 18360 & \\
\hline All & 15977 & & 16352 & \\
\hline \multicolumn{5}{|c|}{ Catastrophic health expenditure (\%) } \\
\hline Urban area & 25.24 & 0.993 & 19.51 & 0.003 \\
\hline Rural area & 25.19 & & 33.33 & \\
\hline SES Index, low level & 26.28 & 0.595 & 28.80 & 0.468 \\
\hline SES Index, high level & 23.08 & & 25.42 & \\
\hline All & 25.21 & & 27.17 & \\
\hline \multicolumn{5}{|c|}{$\begin{array}{l}\text { Note: In this study, we defined catastrophic health expenditure as medical OOPE equalling or } \\
\text { exceeding } 40 \% \text { of the household's expenditure on non-food consumption. }\end{array}$} \\
\hline \multicolumn{5}{|c|}{ * Out-of-pocket expenditure among cancer patients with outpatient visit } \\
\hline ** Out-of-pocket exper & ts with ir & tient care & & \\
\hline
\end{tabular}

Table 4 suggests a positive relationship between cancer treatment and outpatient visit (OR $=2.098,95 \%$ $\mathrm{Cl}=1.453,3.029)$, admission to hospital $(\mathrm{OR}=1.961,95 \% \mathrm{Cl}=1.346,2.857)$ and $\mathrm{CHE}(\mathrm{OR}=1.796,95 \% \mathrm{Cl}$ $=1.231,2.620)$. Chemotherapy $(\mathrm{OR}=2.53,95 \% \mathrm{Cl}: 1.55,4.12)$ and surgery (surgery: $\mathrm{OR}=2.15,95 \% \mathrm{Cl}$ : $1.44,3.20$ ) were each associated with a 2-fold increased risk of $\mathrm{CHE}$, after controlling all sociodemographic covariates. This association was stronger among high SES groups (chemotherapy OR = $3.16,95 \% \mathrm{Cl}: 1.44,6.90$; surgery: $\mathrm{OR}=2.36,95 \% \mathrm{Cl}: 1.24,4.49)$ compared with low SES groups (chemotherapy $\mathrm{OR}=2.77,95 \% \mathrm{Cl}: 1.41,5.41$; surgery $\mathrm{OR}=2.07,95 \% \mathrm{Cl}: 1.22,3.51$ ). There were no significant associations observed for TCM with CHE overall or by SES. 
Table 4

Differential impacts of the cancer treatment on health service use and catastrophic health expenditure

\section{Treatment type \\ Outpatient}

visits
Admission

to hospital
Catastrophic health expenditure

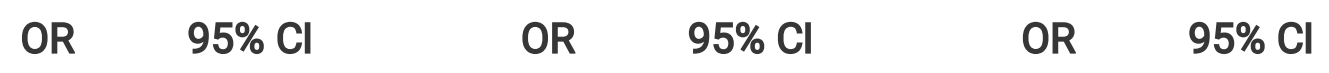

\section{All cancer patients}

\begin{tabular}{|c|c|c|c|c|c|c|c|c|c|}
\hline $\begin{array}{l}\text { Overall cancer } \\
\text { treatment }\end{array}$ & 2.098 & 1.453 & 3.029 & 1.961 & 1.346 & 2.857 & 1.796 & 1.231 & 2.620 \\
\hline TCM only & 2.002 & 0.886 & 4.525 & 0.771 & 0.297 & 1.999 & 1.187 & 0.481 & 2.928 \\
\hline $\begin{array}{l}\text { Western medication } \\
\text { only }\end{array}$ & 1.227 & 0.792 & 1.902 & 1.503 & 0.970 & 2.329 & 1.204 & 0.767 & 1.889 \\
\hline $\begin{array}{l}\text { TCM \& western } \\
\text { medication }\end{array}$ & 1.904 & 1.142 & 3.176 & 1.001 & 0.576 & 1.739 & 1.201 & 0.696 & 2.072 \\
\hline Chemotherapy & 1.823 & 1.115 & 2.979 & 3.622 & 2.233 & 5.874 & 2.530 & 1.551 & 4.126 \\
\hline Surgery & 1.750 & 1.187 & 2.580 & 2.041 & 1.371 & 3.037 & 2.146 & 1.437 & 3.204 \\
\hline Radiation therapy & 0.845 & 0.400 & 1.788 & 3.310 & 1.714 & 6.393 & 1.675 & 0.847 & 3.314 \\
\hline
\end{tabular}

SES Index, low level

\begin{tabular}{|c|c|c|c|c|c|c|c|c|c|}
\hline TCM only & 2.740 & 0.824 & 9.109 & 0.662 & 0.139 & 3.155 & 1.367 & 0.394 & 4.741 \\
\hline $\begin{array}{l}\text { Western medication } \\
\text { only }\end{array}$ & 1.348 & 0.736 & 2.467 & 1.027 & 0.530 & 1.989 & 0.819 & 0.435 & 1.545 \\
\hline $\begin{array}{l}\text { TCM \& western } \\
\text { medication }\end{array}$ & 1.570 & 0.778 & 3.169 & 0.997 & 0.452 & 2.199 & 0.948 & 0.446 & 2.012 \\
\hline Chemotherapy & 2.222 & 1.118 & 4.414 & 3.496 & 1.773 & 6.890 & 2.766 & 1.414 & 5.410 \\
\hline Surgery & 1.422 & 0.833 & 2.425 & 1.811 & 1.031 & 3.183 & 2.072 & 1.224 & 3.507 \\
\hline Radiation therapy & 1.314 & 0.518 & 3.331 & 3.827 & 1.584 & 9.246 & 1.663 & 0.680 & 4.065 \\
\hline
\end{tabular}

SES Index, high level

TCM only

$\begin{array}{lll}1.321 & 0.406 & 4.300\end{array}$

0.791

$0.232 \quad 2.698$

0.956

0.246

3.717

Note: Logistic regressions adjusted for: age, gender, marital status, residence location, region, health insurance. The bold values refer to $\mathrm{P}<0.05$ from the multivariable regression analysis.

*Overall treatment defined as receipt of any TCM or Western medicine treatment

**Western modern medication in this study exclude chemotherapy medications

***Surgery, chemotherapy and radiation each evaluated separately, although patients might receive a combination of all three 


\begin{tabular}{|c|c|c|c|c|c|c|c|c|c|}
\hline \multirow[t]{2}{*}{ Treatment type } & \multicolumn{3}{|c|}{$\begin{array}{l}\text { Outpatient } \\
\text { visits }\end{array}$} & \multicolumn{3}{|c|}{$\begin{array}{l}\text { Admission } \\
\text { to hospital }\end{array}$} & \multicolumn{3}{|c|}{$\begin{array}{l}\text { Catastrophic health } \\
\text { expenditure }\end{array}$} \\
\hline & OR & $95 \% \mathrm{Cl}$ & & OR & $95 \% \mathrm{Cl}$ & & OR & $95 \% \mathrm{Cl}$ & \\
\hline $\begin{array}{l}\text { Western medication } \\
\text { only }\end{array}$ & 1.210 & 0.625 & 2.344 & 2.325 & 1.247 & 4.334 & 1.791 & 0.912 & 3.519 \\
\hline $\begin{array}{l}\text { TCM \& western } \\
\text { medication }\end{array}$ & 2.087 & 0.955 & 4.562 & 0.916 & 0.414 & 2.031 & 1.629 & 0.713 & 3.720 \\
\hline Chemotherapy & 1.338 & 0.636 & 2.817 & 3.864 & 1.875 & 7.962 & 3.156 & 1.442 & 6.907 \\
\hline Surgery & 2.223 & 1.232 & 4.012 & 2.404 & 1.341 & 4.311 & 2.364 & 1.243 & 4.496 \\
\hline Radiation therapy & 0.228 & 0.048 & 1.077 & 2.457 & 0.871 & 6.931 & 1.940 & 0.634 & 5.937 \\
\hline \multicolumn{10}{|c|}{$\begin{array}{l}\text { Note: Logistic regressions adjusted for: age, gender, marital status, residence location, region, health } \\
\text { insurance. The bold values refer to } \mathrm{P}<0.05 \text { from the multivariable regression analysis. }\end{array}$} \\
\hline \multicolumn{10}{|c|}{ *Overall treatment defined as receipt of any TCM or Western medicine treatment } \\
\hline \multicolumn{10}{|c|}{$\star \star$ Western modern medication in this study exclude chemotherapy medications } \\
\hline
\end{tabular}

\section{Discussion}

As this nationally representative study indicated, there was increasing trends in the prevalence of cancer, outpatient and inpatient service use among Chinese middle-aged and elderly adults between 2011 and 2015. About half of cancer patients utilized cancer treatment for their disease, with a higher proportion in the urban versus rural residents in 2015. Those patients with high socio-economic degree received a high proportion of surgery and chemotherapy compared with low SES patients in 2015 . There was also a substantial increase in CHE among rural patients from 2011 to 2015 and a substantial decrease among urban patients in the same time period. Utilization of chemotherapy and surgery appeared to drive the CHE increase, regardless of SES.

There are likely several factors contributing to the observed urban-rural differences in cancer care that needs to be addressed to increase the equitable access to healthcare in future. First, cancer care is provided as specialized services, and generally secondary or higher levels hospitals have the capacity to provide such care. Rural residents have less geographic access to cancer care comparing with urban areas, and some patients need extended travel and additional expenses to urban cities to get specialized cancer services [37]. During the period of the Coronavirus Disease 2019 (COVID-19) pandemic, patients may face more challenges in accessing cancer care. COVID-19 pandemic could disrupt the access to essential healthcare and likely exacerbate existing disparities since rural residents are more likely to be negatively by travel restrictions for access to specialized health services [38-40]. Public health efforts 
will be needed to address the impact of delayed diagnosis and suboptimal care in these rural populations to minimize adverse health outcomes among patients with cancer.

Second, previous studies have documented the urban-rural disparity in availability of medical resources in China [41, 42]. Research has generally found that residents living in rural areas would be less likely to use healthcare services with same quality due to the unbalanced economic development [43, 44]. Consistent with other studies, people in rural areas are more likely to have a shortage of healthcare service providers and lack social supports [45-47]. Previous research suggested that the number of licensed doctors and nurses, medical-technical personnel as well as beds per 1000 population in urban communities increased more than the number in rural communities in China from 2005 to 2017. [48] Registered doctors per thousand populations in urban areas were 2.57 times more than in rural areas in China in 2015 [49]. For this reason, cancer patients in rural areas may prefer using the services from a nearby urban area, even at the cost of higher financial burden.

Third, patients in the rural areas face potentially more financial barrier to cancer care compared with patients in urban areas, likely due to more barriers in physical access to healthcare services, and high percapita payment for cancer care. The social medical insurances likely contributes to urban-rural disparity in $\mathrm{CHE}$ through gaps in coverage and benefit packages [50]. While over 95\% Chinese population are covered by basic medical insurances, the benefits packages can vary significantly across main social health insurances $[5,6,23]$. The per-capita fund of UEBMI is US\$424.7, whereas only $\$ 61.2$ for NCMS in 2015 [25]. The co-payment rates of NCMS (73.4\%) was higher than UEBMI (36.8\%) and URBMI (50.7\%) in 2008 [51]. Herein, cancer patients in rural regions have lower reimbursement rates and lower annual maximum payment from insurance. Additionally, patients seek care from other county/prefectures usually have reduced reimbursement rates. In this case, if cancer patients from rural areas have to utilize cancer care from another city, they have to pay more proportion of their bill out-of-pocket. Such a heavy financial burden likely compels low SES and rural patients away from cancer treatment utilization, possibly explaining the large urban-rural disparity in inpatient care use than outpatient visits. Paying more attention to out of pocket expenses and financial implications of cancer treatment across health insurance schemes is need in future.

Finally, while the expenditures for cancer care are increasing in rural areas as well as urban areas, the uneven nature of economic development and low-level disposable income of rural residents may further contribute the urban-rural disparities in financial risk and treatment burden. The disposable income of urban citizens was 31,195 RMB per capita, which was three times higher than that of residents living in rural areas $(11,422 \mathrm{RMB})$ in China in 2015 [52]. Medical expenditures due to cancer treatment, specifically surgery and chemotherapy, is likely to have significantly greater impact on rural patients, leading to increased risk of CHE and impoverishment [52]. In addition, since NCMS and URBMI were mainly financed by local county-level governments at the early stage of China new health system reform, the quality of benefit packages likely depends on local economic development [49]. 
We observed that those cancer patients with high socio-economic level were less likely to experience $\mathrm{CH}$ than low SES individuals, and by 2015 , rural cancer patients had almost double the prevalence of CHE compared with urban cancer patients, suggesting that a potential unintended consequence of the health reform is widening of rural-urban disparities in CHE. The findings are consistent with previous research on trends in financial burden among residents with NCDs in China [25,53]. Recent studies have documented a rapid rise in healthcare cost for cancer patients in China, however data on the population-level economic burden of cancers is limited and the reported expenditure per patient may be underestimated [54-60]. For example, a systematic review of the economic burden of liver cancer shows an increase in expenditure indicators (direct medical expenditure, annual expenditure per visit and annual expenditure per diem) from 1996 to 2015, with medication costs accounting for more than half of the overall expenditure (56. 6\%) [57]. For colorectal cancer, the annual growth rate for medical expenditure per patient, per visit and per day increased from 6.9-7.8\% from 1996 to 2015, respectively [58].

\section{Policy Implications}

The health insurance programs in China has had some positive impacts on healthcare utilization. For instance, we observed that outpatient visits and admissions in the past months increased between 2011 and 2015 in all socio-demographic groups examined. However, there are still challenges especially related to costs. Overall, the burden of cancer among Chinese adults is increasing and about one-fourth cancer patients experienced CHE. Yet disparities among urban-rural, and different SES still exist, even after the implementation of the national health insurance scheme.

To reduce financial burden of cancer and bridge the SES gaps, comprehensive changes to health insurance benefit packages and healthcare resource allocation are needed to ensure universal, affordable and patient-centered health coverage. First, the URBMI and the NCMS need to be further integrated in contribution, benefit package, as well as financial risk protection to accelerate the equitable access to health service in both urban and rural areas. Secondly, social health insurance benefit packages need to be further expanded. Health services, including medicines, with proved cost-effectiveness evidence can be added to the National Insurance Reimbursable List (NIRL). For instance, 17 and 22 anti-cancer medicines have been elected into the NIRL with significant price cut in 2018 and 2019, respectively, and have reduced the financial burden of cancer patients. [61, 62]. Thirdly, while the National Health Insurance is aiming at providing financial protection for essential care, the Critical Illness Medical Insurance (CIMI) should play an increasing role in providing financial support on catastrophic expenses, including cancer patients. In particular, the current CIMI in most regions followed the NIRL which prioritize the essential care [63]. To provide better protection on catastrophic expenses, CIMI should explore additional coverage on other therapies with proven health benefits. Furthermore, enhancing the capacity of the National Public Health Initiative can enhance cancer prevention strategies such as routine screening and case management. This might lead to early detection of cancer, reduced financial burden and improved cancer outcomes if diagnosed at early stages when cancer treatments are most effective. This approach might be especially critical given healthcare disruptions due to the COVID-19 pandemic. 
Given unprecedented effects of the COVID-19 on global healthcare systems, it would be inevitable that the pandemic would substantially negatively influence the cancer patients, health practitioners, and healthcare systems $[64,65]$. Due to the COVID-19 outbreak, several healthcare services have to be postponed and even cancelled in many countries, leaving patients without access to essential health services [66]. Globally, $42 \%$ countries have partially or completely disrupted services for cancer treatment/therapy [67]. During the COVID-19 period, the waiting time for surgery and days in hospital was longer, and total expenditures for inpatient care increased in China [68]. To cancer patients, this means delayed diagnosis or treatment and further lead to disease progression. In many countries, teleconsultations became an emerging form to provide essential healthcare while limit the spread of COVID19 [69]. However, the capacity for providing telemedicine varied greatly, and there is limited coverage on telemedicine by China's social health insurances, which may potentially make further disparities in health service use. In the post COVID-19 era, how to balance the health system emergency reaction with essential healthcare, how to best utilize new technology to improve access and equity will be emerging health policy issues.

\section{Strengths and Limitations}

This research utilized data from a China nationally representative study to investigate the trends and disparity in cancer treatments, healthcare service utilization and CHE from 2011 to 2015. Our study could contribute to a deeper understanding of socio-economic and rural-urban disparities in cancer treatment, health service utilization and expenditures. There are several significant limitations. This study used the measurements based on self-reported information of diagnosed cancer, treatment type and healthcare service use, which may lead to underestimate the prevalence of cancer and an under-reported utilization due to the recall bias [57]. Medical information regarding the severity of cancers had not been collected. The CHARLS survey only considered those middle-aged and elderly Chinese residents. Future research should also focus on the younger adults to explore the trends and disparities in cancer care and financial burden. Moreover, about 20\% of total participants in CHARLS are with missing values of key dependent and independent variables during the survey conducted in 2011 and 2015.

\section{Conclusions}

The burden of cancer among Chinese adults is increasing. Socio-economic and urban-rural disparities in cancer treatment and health service use were largely determined by patient financial capability in China. The current social health insurance schemes are insufficient to address these disparities. A comprehensive health insurance policy of further expanding benefit packages and strengthening the Public Medical Assistance System, is essential for Chinese people with cancers.

\section{Abbreviations}

NCDs: Non-communicable diseases; CHE: catastrophic health expenditure; UEBMI: Urban Employees Basic Medical Insurance; URBMI: Urban Residents Basic Medical Insurance; NCMS: New Rural Cooperative Medical System; SES: Socio-economic status; CHARLS: China Health and Retirement 
Longitudinal Study; PPS: probability-proportionate-to-size; TCM: Chinese traditional medication; OOP: outof-pocket payments; OR: odds ratio; NIRL: National Insurance Reimbursable List; COVID-19: Coronavirus Disease 2019.

\section{Declarations}

\section{Ethics approval and consent to participate}

The Biomedical Ethics Review Committee of Peking University approved the CHARLS study, and all interviewees were required to provide informed consent. The ethical approval number was IRB0000105211015.

\section{Consent for publication}

Not applicable.

\section{Availability of data and materials}

The datasets generated and analyzed during the current study are available in the China Health and Retirement Longitudinal Study repository. http://charls.pku.edu.cn/pages/data/111/en.html.

\section{Competing interests}

The authors declared that they have no competing interests.

\section{Funding}

No funding was obtained for this study

\section{Acknowledgments}

We gratefully acknowledge the China Health and Retirement Longitudinal Study team for providing data and training in using the datasets. We are grateful to the students who participated in the survey for their cooperation. The authors thank all volunteers and staff involved in this research.

\section{Authors' contributions}

YZ and ST conceived and designed the study. YZ carried out the initial analysis. YZ, ST and TA interpreted the data. WM and $Y Z$ analysed the literature. $Y Z$ and $W M$ wrote the first draft of the paper. TA, ST and WM provided advice on the first draft and revised the article critically for important intellectual content. All authors reviewed and had final approval of the submitted and published versions.

\section{References}


1. Bray F, Ferlay J, Soerjomataram I, Siegel R, Torre L, Jemal A. Global cancer statistics 2018: GLOBOCAN estimates of incidence and mortality worldwide for 36 cancers in 185 countries. CA A Cancer J Clin. 2018;68:394-424. https://doi.org/10.3322/caac.21492.

2. Fang $\mathrm{H}$, Eggleston $\mathrm{K}$, Hanson $\mathrm{K}$, Wu M. Enhancing financial protection under China's social health insurance to achieve universal health coverage. BMJ. 2019;365:I2378. https://doi.org/10.1136/bmj.I2378.

3. Liu H, Gao S, Rizzo J. The expansion of public health insurance and the demand for private health insurance in rural China. China Econ Rev. 2011;22:28-41. https://doi.org/10.1016/j.chieco.2010.08.006.

4. Mao W, Tang S, Zhu Y, Xie Z, Chen W. Financial burden of healthcare for cancer patients with social medical insurance: A multi-centered study in urban China. Int J Equity Health. 2017;16:180. https://doi.org/10.1186/s12939-017-0675-y.

5. Meng Q, Xu L, Zhang Y, Qian J, Cai M, Xin Y, Gao J, Xu K, Boerma JT, Barber SL. Trends in access to health services and financial protection in China between 2003 and 2011: A cross-sectional study. Lancet. 2012;379:805-14. https://doi.org/10.1016/S0140-6736(12)60278-5.

6. Meng Q, Fang H, Liu X, Yuan B, Xu J. Consolidating the social health insurance schemes in China: Towards an equitable and efficient health system. Lancet. 2015;386:1484-92. https://doi.org/10.1016/S0140-6736(15)00342-6.

7. Chatfield M. Primary Health Care: The Chinese Experience. Health Care Manag Rev. 1984;9:82.

8. Kumachev A, Trudeau ME, Chan KKW. Associations among socioeconomic status, patterns of care, and outcomes in breast cancer patients in a universal health care system: Ontario's experience. Cancer. 2016;122:893-8.

9. Aileen T, Rachael GH, Linda S. "It's at a Time in Your Life When You Are Most Vulnerable": A Qualitative Exploration of the Financial Impact of a Cancer Diagnosis and Implications for Financial Protection in Health. PLoS ONE. 2013;8:e77549.

10. Derouen MC, Parsons HM, Kent EE, Pollock BH, Keegan THM. Sociodemographic disparities in survival for adolescents and young adults with cancer differ by health insurance status. Cancer Causes Control. 2017;28:841-51.

11. Penson DF, Stoddard ML, Pasta DJ, Lubeck DP, Flanders SC, Litwin MS. The association between socioeconomic status, health insurance coverage, and quality of life in men with prostate cancer. $J$ Clin Epidemiol. 2001;54:350-8.

12. Fei $X$, Wu J, Kong Z, Christakos G. Urban-Rural Disparity of Breast Cancer and Socioeconomic Risk Factors in China. PLoS ONE. 2015;10:e0117572.

13. Zhang Y, Bu Y, Gao H. Rural-urban disparities of breast cancer patients in China. Med Oncol. 2012;30:387.

14. Wen D, Wen X, Yang Y, Chen Y, Wei L, He Y, Shan B. Urban rural disparity in female breast cancer incidence rate in China and the increasing trend in parallel with socioeconomic development and urbanization in a rural setting. Thorac Cancer. 2017;9:262-72. 
15. Wen X, Wen D, Yang Y, Chen Y, Wang G, Shan B. Urban-Rural Disparity in Helicobacter Pylori InfectionRelated Upper Gastrointestinal Cancer in China and the Decreasing Trend in Parallel with Socioeconomic Development and Urbanization in an Endemic Area. Ann Glob Health. 2017;83:44462.

16. Wen D, Zou W, Wen X, Yang Y, Chen Y, He Y, Wang G, Shan B. Urban-rural disparity in colorectal cancer incidence and increasing trend in relation to socioeconomic development and urbanization in China. J Int Med Res. 2018;46:4181-96.

17. Xia C, Ding C, Zheng R, Zhang S, Zeng H, Wang J, Liao Y, Zhang N, Yang Z, Chen W. Trends in geographical disparities for cervical cancer mortality in China from 1973 to 2013: A subnational spatio-temporal study. Chin J Cancer Res. 2017;29:487-95.

18. Jiang X, Cai S, Hu Y, Ye D, Li Q, Chen K, Jin M. Sex disparities in cancer incidence in Jiashan County, China, 1995-2014. Cancer Epidemiol. 2017;50:46-52.

19. Yang L, Zhang $X$, Yang $X$, Yang J, Wang Z, Chen H,. et al. Lung Cancer Treatment Disparities in China: A Question in Need of an Answer. Oncologist. 2014;19:1084-90.

20. Zhao Y, Oldenburg B, Mahal A, Haregu T, Katar A, Zhang L. Trends and inequalities in the health care and hypertension outcomes in China, 2011 to 2015. Int J Environ Res Public Health. 2019;16:4578.

21. Liu X, Sun X, Zhao Y, Meng Q. Financial protection of rural health insurance for patients with hypertension and diabetes: Repeated cross-sectional surveys in rural China. BMC Health Serv Res. 2016;16:481.

22. Zhao Y, Oldenburg B, Zhao S, Haregu T, Zhang L. Temporal trends and geographic disparity in hypertension care in China. J Epidemiol. 2019; 30. doi:10.2188/jea.JE20190029.

23. Zhao Y, Oldenburg B, Mahal A, Lin Y, Tang S, Liu X. Trends and socioeconomic disparities in catastrophic health expenditure and health impoverishment in China: 2010 to 2016. Trop Med Int Health. 2019;24:236-47.

24. Yin $P$, Zhang M, Li Y, Jiang Y, Zhao W. Prevalence of COPD and its association with socioeconomic status in China: Findings from China Chronic Disease Risk Factor Surveillance 2007. BMC Public Health. 2011;11:586.

25. Zhao Y, Atun R, Oldenburg B, McPake B, Tang S, Mercer S, Cowling T, Sum G, Qin V, Lee J. Physical multimorbidity, health service use, and catastrophic health expenditure by socioeconomic groups in China: an analysis of population-based panel data. Lancet Global Health. 2020;8:e840-9.

26. Yao N, Wang J, Cai Y, Yuan J, Wang H, Gong J, Anderson R, Sun X. Patterns of cancer screening, incidence and treatment disparities in China: Protocol for a population-based study. BMJ Open. 2016;6:e012028.

27. Zhao Y, Hu Y, Smith J, Strauss J, Yang G. Cohort Profile: The China Health and Retirement Longitudinal Study (CHARLS). Int J Epidemiol. 2012;43:61-8.

28. Raban M, Dandona R, Dandona L. Variations in catastrophic health expenditure estimates from household surveys in India. Bull World Health Organ. 2013;91:726-35. 
29. Brinda E, Kowal P, Attermann J, Enemark U. Health service use, out-of-pocket payments and catastrophic health expenditure among older people in India: The WHO Study on global AGEing and adult health (SAGE). J Epidemiol Community Health. 2015;69:489-94.

30. Ranson MK. Reduction of catastrophic health care expenditures by a community-based health insurance scheme in Gujarat, India: Current experiences and challenges. Bull World Health Organ. 2002;80:613-21.

31. Li Q. Social class in current China: measurement and analysis. Beijing: Beijing Normal University Press; 2010. (in Chinese).

32. Liu H. Research on English learning motivation: a social class perspective. Journal of Northeast Normal University (Philosophy and Social Sciences). 2014. 256-261. (in Chinese).

33. Xu H, Guo Y, Shi S. The impact of farmer differentiation on the willingness of farmland transfer of the households: based on structural equation model. China Land Sciences. 2012;26:74-9. (in Chinese).

34. Zhang J, Liu Y, Du Q. Comparing sport consumer behaviors across social strata. Consumer Economics. 2012;28:81-5. (in Chinese).

35. Mingling C, Yikang W, Hiroto N,. et al. Socioeconomic Status and Physical Activity in Chinese Adults: A Report from a Community-Based Survey in Jiaxing, China. Plos One. 2015;10(7):e0132918.

36. Duncan OD. (1961) A socioeconomic index for all occupations; Reiss A.J., editor. New York: Free Press. 1961; 109-138.

37. Li J, Shi L, Liang L, Ding G, Xu L. Urban-Rural Disparities in Health Care Utilization among Chinese Adults from 1993 to 2011. BMC Health Services Research. 2018;18:102.

38. Liang W, Guan W, Chen R, Wang W, Li j, Xu K, et al. Cancer patients in SARS-CoV-2 infection: a nationwide analysis in China. The Lancet Oncology. 2020;21(3):335-7.

39. Wu Z, McGoogan JM. Characteristics of and Important Lessons From the Coronavirus Disease 2019 (COVID-19) Outbreak in China: Summary of a Report of 72314 Cases From the Chinese Center for Disease Control and Prevention. JAMA. 2020;323(13):1239-42.

40. Sud A, Torr B, Jones M, Houlston R, Turnbull C. Effect of delays in the 2-week-wait cancer referral pathway during the COVID-19 pandemic on cancer survival in the UK: a modelling study. The Lancet Oncology. 2020;21(8):1035-44.

41. Chen $Y$, Yin Z, Xie Q. Suggestions to ameliorate the inequity in urban/rural allocation of healthcare resources in China. Int J Equity Health. 2014;13:34.

42. Shi LY. Health-care in China - a rural-Urban comparison after the socioeconomic reforms. Bull World Health Organ. 1993;71(6):723-36.

43. Wu RX, Cai Y, Lan L, Fan ZW, Xue M. Trend analysis on the allocation of primary health care resources between urban and rural areas in China from 2008 to 2015. ChinHealth Resour. 2017;3:20-3. 
44. Chen $Y$, Yin Z, Xie Q. Suggestions to ameliorate the inequity in urban/rural allocation of healthcare resources in China. Int J Equity Health. 2014;13:34.

45. Weaver KE, Geiger AM, Lu L, Case LD. Rural-urban disparities in health status among US cancer survivors. Cancer. 2013;119(5):1050-7.

46. Kroneman $M$, Verheij $R$, Tacken $M$, van der Zee J. Urban-rural health differences: primary care data and self reported data render different results. Health Place. 2010;16(5):893-902.

47. Sibley LM, Weiner JP. An evaluation of access to health care services along the rural-urban continuum in Canada. BMC Health Serv Res. 2011;11:20.

48. Tao W, Zeng Z, Dang H, Li P, Kominski G. Towards universal health coverage: achievements and challenges of 10 years of healthcare reform in china. British Medical Journal Global Health. 2020;5(3):e002087.

49. China NHaFPCo. Health and family planning statistics yearbook. (2015). Beijing: China Union Medical University Press. 2015.

50. Yongjian $\mathrm{X}$, Jie $\mathrm{M}, \mathrm{Na} \mathrm{W}$, et al. Catastrophic health expenditure in households with chronic disease patients: A pre-post comparison of the New Health Care Reform in Shaanxi Province, China. PLoS ONE. 2018;13(3):e0194539.

51. Li X, Zhang W. The impacts of health insurance on health care utilization among the older people in China. Social ence Medicine. 2013;85(Complete):59-65.

52. Shen Lamson Lin. Inequities in Access: The Impact of a Segmented Health Insurance System on Physician Visits and Hospital Admissions Among Older Adults in the 2014 China Family Panel Studies. Int J Health Serv. 2019;50(1):1-27.

53. Gwatidzo SD, Stewart Williams J. Diabetes mellitus medication use and catastrophic healthcare expenditure among adults aged 50 + years in China and India: results from the WHO study on global AGEing and adult health (SAGE). BMC Geriatr. 2017; 17(14).

54. Yao F, Shi CL, Liu CC, et al. Economic burden of stomach cancer in China during 1996-2015: a systematic review. Zhonghua Yu Fang Yi Xue Za Zhi. 2017;51(8):756-62.

55. Yue C, Baohu Y, Zhou Gongwei. Analysis of Direct Economic Burden and Average Hospitalization Cost of Lung Cancer in China in 2011-2015. Chinese Journal of Health Statistics. 2018;35(03):169.

56. Guo LW, Shi CL, Huang HY, Wang L, Shi JF. Economic burden of esophageal cancer in china from 1996 to 2015: a systematic review. Zhong hua Liu xing bing xue Za zhi. 2017;38(1):102-9.

57. Jun Yang L, Wang C, Shi H, Huang Y, Wang J, Li J, Zhao C, Qu M, Dai L, Yang. Jufang Shi. Economic burden of liver cancer in China during 1996-2015: a systematic review. Chinese Journal of Disease Control Prevention. 2017;21(008):835-40.

58. Liu C, Huang H, Shi J. Economic Burden of Colorectal Cancer in China from 1996 to 2015: A Systematic Review. China Cancer. 2017;26(11):859-67. 
59. Le Wang X, Yue J, Shi S, He J, Zhu C, Shi H, Huang C, Liu Y, Fang M, Dai. Economic burden of breast cancer in China in the past two decades. Chinese Journal of Disease Control Prevention. 2017;25(002):143-6.

60. Shi J, Shi C, Yue X, Huang H, Wang L, Li J, Lou P, Mao A, Dai M. Economic burden of cancer in China during 1996-2014: a systematic review. Chinese Journal of Oncology. 2016;38(12):929-41.

61. The National Healthcare Security Administration. A notice to include 17 anticancer drugs into the scope of the "National Basic Medical Insurance, Work Injury Insurance and Maternity Insurance Drug Catalogue (2017 Edition)" category B. http://www.gov.cn/xinwen/201810/10/content_5328891.htm. (In Chinese, access, 10 Oct, 2018).

62. The State Council of the People's Republic of China. Including 22 anticancer drugs and 14 chronic disease drugs into the "National Basic Medical Insurance Drug Catalogue.

http://www.gov.cn/xinwen/2019-12/17/content_5461773.htm. (In Chinese, access, 17 Dec, 2019 ).

63. Mao W, Zhang L, Chen W. Progress and policy implication of the Insurance Programs for Catastrophic Diseases in China. The International Journal of Health Planning Management. 2017;32(3):299-306.

64. Moujaess E, Kourie H, Ghosn M. Cancer patients and research during COVID-19 pandemic: A systematic review of current evidence. Crit Rev Oncol/Hematol. 2020;150:102972.

65. Hwee J, Chiew J, Sechachalam S. The Impact of Coronavirus Disease 2019 (COVID-19) on the Practice of Hand Surgery in Singapore. The Journal of Hand Surgery. 2020; 45(6). https://doi.org/10.1016/j.jhsa.2020.04.023.

66. Chang E, Liu J. Flattening the curve in oncologic surgery: Impact of Covid on surgery at tertiary care cancer center. J Surg Oncol. 2020. DOI:10.1002/jso.26056.

67. World Health Organization. COVID-19 significantly impacts health services for noncommunicable diseases. 2020. https://www.who.int/news/item/01-06-2020-covid-19-significantly-impacts-healthservices-for-noncommunicable-diseases.

68. Li Y, He C, Liu Y, Zhao P, Du X. The Impact of COVID-19 on Gastric Cancer Surgery: A Single-center Retrospective Study Based on Real-world Data from China. 2020. DOI: 10.21203/rs.3.rs-35676/v1.

69. Richards M, Anderson M, Carter P, et al. The impact of the COVID-19 pandemic on cancer care. Nature Cancer. 2020; (6): 565-7. https://doi.org/10.1038/s43018-020-0074-y.

\section{Supplementary Files}

This is a list of supplementary files associated with this preprint. Click to download.

- NoveltylmpactStatements.docx 